\title{
Comparison of the Mechanical Properties of a New Capacity-expanding and Energy-saving Conductor and Traditional Conductors
}

\author{
Yuchen He, Bin Song ${ }^{*}$ and Min Gao \\ School of Electrical Engineering, Wuhan University, Wuhan, China \\ ${ }^{*}$ Corresponding author
}

\begin{abstract}
The mechanical properties of a traditional steel-cored aluminum strand conductor and a new capacity-expanding and energy-saving conductor for a typical $500 \mathrm{kV}$ transmission line are compared to provide a reference for the conductor lectotype of transmission lines. The study objects are a traditional steel-cored aluminum strand and three new capacity-increasing and energy-saving conductors (a new steel-cored aluminum strand of high conductivity, a new total aluminum alloy aluminum stranded conductor, and a new total aluminum alloy aluminum conductor of medium tenacity). The sag characteristics, icing overload capacity, and load bearing characteristics of these conductors are comprehensively compared and analyzed to obtain the mechanical properties of each conductor. The analytical results show that in the engineering of a $500 \mathrm{kV}$ transmission line, the new steel-cored aluminum strand of high conductivity has the best sag characteristics, icing overload capacity and combined load capacity.
\end{abstract}

Keywords- new capacity-expanding and energy-saving conductor; mechanical properties; comparative analysis

\section{INTRODUCTION}

As the national economy develops rapidly and continuously, the social demands for power utilization increase each year, coupled with an increasingly large imbalance between the power utilization demand and electricity supply ${ }^{[1]}$ New capacity-expanding and energy-saving conductors have emerged along with the increasing demands for capacity increases and energy savings in power grids. An overhead power transmission conductor must have a certain mechanical strength to support its deadweight and natural external loads, such as wind load and ice load. Thus, research on the mechanical properties of new capacity -expanding and energy-saving conductors is an important step in conductor lectotype.

Current research on the mechanical properties of conductors mainly focuses on a specific span and specific ice thickness ${ }^{[2-4]}$ or only compares new capacity-expanding and energy-saving conductors ${ }^{[5-8]}$, lacking comparisons between new capacity-expanding and energy-saving conductors and traditional conductors in different representative spans and ice thicknesses.

The paper takes a typical $500 \mathrm{kV}$ typical transmission line as the study subject and selects three representative spans of 400,500 and $600 \mathrm{~m}$ and two ice thicknesses of 10 and $20 \mathrm{~mm}$ to compare three new capacity-expanding and energy-saving conductors (new steel-cored aluminum strand of high conductivity, new total aluminum alloy aluminum strand, and new total aluminum alloy aluminum conductor of medium tenacity) and a traditional steel-cored aluminum strand in terms of their high-temperature sag performance, icing overload capacity, and weight bearing power. The results show that the new steel-cored aluminum strand of high conductivity has the best sag characteristics, icing overload capacity and combined load capacity.

\section{CONDUCTOR SAG CHARACTERISTIC}

Conductor sag is related to the linear expansion coefficient $^{[9]}$, structural design, manufacturing process and maximum stress of the conductor. An overhead conductor shrinks due to temperature fluctuations. To adapt to such telescoping, the sag of the conductor increases accordingly. Now, consider the conductor's sag characteristics in high temperature; then, the calculation steps of the conductor's sag are as follows ${ }^{[10]}$ :

First Calculate The Specific Load $g_{n}$ and stress $\sigma_{n}$ under the condition to be calculated according to the state equation of the conductor with the following formulas:

$$
\begin{aligned}
& \sigma_{n}{ }^{2}\left(\sigma_{n}+A\right)=B \\
& \mathrm{~A}=\frac{\mathrm{Eg}_{m}^{2} l_{r e}^{2}}{24 \sigma_{m}}-\sigma_{m}+\alpha E\left(t_{n}-t_{m}\right) \\
& \mathrm{B}=\frac{E g_{n}^{2} l_{r e}^{2}}{24}
\end{aligned}
$$

where $t_{m}$ is the temperature under the initial meteorological conditions, ${ }^{\circ} C ; t_{n}$ is the temperature under the meteorological conditions to be calculated, ${ }^{\circ} C ; g_{m}$ is the specific load under the initial meteorological conditions, $\left(\mathrm{N} / \mathrm{m} \cdot \mathrm{mm}^{2}\right) ; g_{n}$ is the specific load under the meteorological conditions to be calculated, $\left(N / m \cdot \mathrm{mm}^{2}\right)$; $\sigma_{m}$ is the stress when the temperature is $t_{m}$ and the specific load is $g_{m}, \mathrm{MPa} ; \sigma_{n}$ is the stress when the temperature is 
$t_{n}$ and the specific load is $g_{n}, \mathrm{MPa} ; \alpha$ is the linear expansion coefficient, $1 /{ }^{\circ} C ; E$ is the elastic coefficient of the conductor, $N / \mathrm{mm}^{2}$; and $l_{r e}$ is the representative span for the strain section, $m$.

(2) Then, calculate the sag according to the following sag calculation formula:

$$
f_{x}=\frac{g_{n}}{2 \sigma_{n}} l_{a} l_{b}
$$

where $f_{x}$ is the maximal high-temperature sag, $m ; g_{n}$ is the specific load under the meteorological conditions to be calculated, $\left(\mathrm{N} / \mathrm{mm}^{2}\right) ; \sigma_{n}$ is the stress when the temperature is $t_{n}$ and the specific load is $g_{n}, \mathrm{MPa}$; and $l_{a}$ and $l_{b}$ are the horizontal distances from the scissor crossing to be verified to the tower, $m$.

Select the representative spans for the strain section $l_{r e}$ as 400, 500 and $600 \mathrm{~m}$ and the ice thicknesses as 10 and $20 \mathrm{~mm}$. Then, take the average air temperature $15{ }^{\circ} \mathrm{C}$ as the temperature $t_{m}$ in under the initial meteorological conditions, and take the maximum temperature of the conductor $+80^{\circ} \mathrm{C}$ as the temperature $t_{n}$ under the meteorological conditions to be calculated. The high-temperature sag characteristics of the four conductors can be obtained by Formulas (1)-(4), and the results are shown in TABLE 1.

TABLE I. CONDUCTOR'S HIGH-TEMPERATURE SAG CHARACTERISTICS

\begin{tabular}{|c|c|c|c|c|c|c|}
\hline $\begin{array}{l}\text { Conductor's } \\
\text { high-temperature } \\
\text { sag characteristics }\end{array}$ & $\begin{array}{l}400 \\
/ 10\end{array}$ & $\begin{array}{l}400 \\
/ 20\end{array}$ & $\begin{array}{l}500 \\
/ 10\end{array}$ & $\begin{array}{l}500 \\
/ 20\end{array}$ & $\begin{array}{l}600 \\
/ 10\end{array}$ & $\begin{array}{l}600 \\
/ 20\end{array}$ \\
\hline Traditional steel-cored aluminum strand & 423 & $\begin{array}{ll}18 . \\
013\end{array}$ & $\begin{array}{c}18 . \\
952\end{array}$ & $\begin{array}{l}28 . \\
029\end{array}$ & $\begin{array}{l}27 . \\
882\end{array}$ & $\begin{array}{c}40 . \\
268\end{array}$ \\
\hline $\begin{array}{l}\text { New steel-cored aluminum strand of high } \\
\text { conductivity }\end{array}$ & 71 & $88^{9.9}$ & 11 & $\begin{array}{l}15 . \\
819\end{array}$ & $\begin{array}{l}17 . \\
856\end{array}$ & $\begin{array}{c}22 . \\
693\end{array}$ \\
\hline $\begin{array}{l}\text { New total aluminum alloy aluminum } \\
\text { strand }\end{array}$ & 12. & $\begin{array}{ll}18 . \\
626\end{array}$ & 192 & $\begin{array}{l}28 . \\
988\end{array}$ & $\begin{array}{c}27 \\
242\end{array}$ & $\begin{array}{c}41 . \\
651\end{array}$ \\
\hline $\begin{array}{l}\text { New total aluminum alloy aluminum } \\
\text { conductor of medium tenacity }\end{array}$ & $\begin{array}{l}8.0 \\
79\end{array}$ & $\begin{array}{c}11 . \\
456\end{array}$ & $\begin{array}{l}12 . \\
316\end{array}$ & $\begin{array}{l}18 . \\
006\end{array}$ & $\begin{array}{c}17 . \\
443\end{array}$ & $\begin{array}{l}26 . \\
018\end{array}$ \\
\hline
\end{tabular}

According to Table 1, except for the fact that the new total aluminum alloy strand and traditional steel-cored aluminum strand have identical sag performances, the other two new conductors both perform better than the traditional steel-cored aluminum strand, with the new steel-cored aluminum strand of high conductivity having the best sag performance.

The new steel-cored aluminum strand of high conductivity also has more significant advantages under large spans, and it can directly lower the nominal height of the tangent tower by $5 \mathrm{~m}$ under ideal conditions compared with that of traditional steel-cored aluminum strand.

\section{CONDUCTOR'S ICING OVERLOAD CAPACITY}

When calculating the icing overload capacity, the maximum tension at the sag nadir should not exceed $60 \%$ of the rated breaking force and the maximum tension at the suspension point should not exceed $66 \%$ of the rated breaking force. According to the literature [11], the conductor's icing overload capacity can be obtained as follows:

$$
\begin{aligned}
& g_{n}=\sqrt{\left(\sigma_{n}-\sigma_{m}+\frac{g_{m}{ }^{2} l_{r e}{ }^{2} E}{24 \sigma_{m}{ }^{2}}\right) \square \sqrt{\frac{24 \sigma_{n}{ }^{2}}{l_{r e}{ }^{2} E}}} \\
& b=-\frac{d}{2} \pm \sqrt{\left(\frac{d}{2}\right)^{2}+\frac{\left(g_{n}-g_{m}\right) \square s}{0.02772}}
\end{aligned}
$$

where $g_{m}$ is the specific load under the initial meteorological conditions, $\left(\mathrm{N} / \mathrm{m} \cdot \mathrm{mm}^{2}\right) ; g_{n}$ is the specific load under the meteorological conditions to be calculated, $\left(\mathrm{N} / \mathrm{m} \cdot \mathrm{mm}^{2}\right) ; \sigma_{m}$ is the stress when the temperature is $t_{m}$ and the specific load is $g_{m}, \mathrm{MPa} ; \sigma_{n}$ is the stress when the temperature is $t_{n}$ and the specific load is $g_{n}, \mathrm{MPa} ; \alpha$ is the linear expansion coefficient, $1 /{ }^{\circ} C ; E$ is the conductor's elastic coefficient, $N / \mathrm{mm}^{2} ; l_{r e}$ is the representative span of the strain section, $m ; d$ is the diameter of the conductor, $m$; and $s$ is the conductor's 
cross-sectional area, $\mathrm{mm}^{2}$

TABLE 2.

The icing overload capacity of the conductor is obtained according to Formulas (5) and (6), and the results are shown in

TABLE II. CONDUCTOR'S ICING OVERLOAD CAPACITY

\begin{tabular}{|c|c|c|c|c|c|c|}
\hline $\begin{array}{l}\text { Conductor's } \\
\text { icing overload } \\
\text { capacity }\end{array}$ & $400 / 10$ & $400 / 20$ & $500 / 10$ & $500 / 20$ & $600 / 10$ & $600 / 20$ \\
\hline Traditional steel-cored aluminum strand & 27.94 & 37.94 & 26.29 & 36.99 & 25.32 & 36.46 \\
\hline $\begin{array}{l}\text { New steel-cored aluminum strand of high } \\
\text { conductivity }\end{array}$ & 37.27 & 44.06 & 33.27 & 41.27 & 30.69 & 39.59 \\
\hline New total aluminum alloy aluminum strand & 26.57 & 37.18 & 25.40 & 36.31 & 24.63 & 35.82 \\
\hline $\begin{array}{l}\text { New total aluminum alloy aluminum } \\
\text { conductor of medium tenacity }\end{array}$ & 33.83 & 41.48 & 30.48 & 39.28 & 28.34 & 37.98 \\
\hline
\end{tabular}

According to TABLE 2, the newly configured steel-cored aluminum strand of high conductivity has the best icing overload capacity under different representative spans and different ice zones, and the newly configured total aluminum alloy strand has the second best performance, $10-30 \%$ higher than that of the steel-cored aluminum strand. The new total aluminum alloy aluminum strand of medium tenacity and traditional steel-cored aluminum strand have similar icing overload capacities; however, they can all meet the requirements of $10 \mathrm{~mm}$ and $20 \mathrm{~mm}$ ice thicknesses with some margin of safety.

\section{CONDUCTOR'S COMBINED LOAD CAPACITY}

Under the effect of wind and icing, the combined load for the conductor of overhead transmission lines can be broken up into a horizontal component and a normal component, with the former being the horizontal wind load of the conductor and the latter being the load produced by conductor's deadweight and ice weight ${ }^{[12-13]}$ (the influence of pneumatic transverse force produced by the Karman vortex is not considered here). This paper studies the conductor's combined load capacity under meteorological conditions for typical $500 \mathrm{kV}$ transmission lines. The meteorological conditions are as shown in TABLE 3.

TABLE III. METEOROLOGICAL CONDITIONS

\begin{tabular}{|c|c|c|c|}
\hline Representative condition & Temperature $\left({ }^{\circ} \mathrm{C}\right)$ & Wind speed $(\mathrm{m} / \mathrm{s})$ & Ice thickness $(\mathrm{mm})$ \\
\hline Minimum air temperature & -10 & 0 & 0 \\
\hline Average air temperature & 15 & 0 & 0 \\
\hline Maximal gale & 10 & 27 & 0 \\
\hline
\end{tabular}

\section{A. Conductor's vertical load capacity}

The conductor's vertical load can be computed as

$$
G=g S l_{v}+G_{i}
$$

where $\mathrm{G}$ is the vertical load of the conductor, $N ; g$ is the vertical specific load of the conductor, $\left(\mathrm{N} / \mathrm{m} \cdot \mathrm{mm}^{2}\right)$; $l_{v}$ is the vertical span, $m$; and $G_{i}$ is the total weight of the insulator string, $N$.

According to Formula (7), the vertical load of the three conductors under the conditions of average temperature and icing is obtained, and the results are shown in TABLE 4. 
TABLE IV. CONDUCTOR'S VERTICAL LOAD CAPACITY

\begin{tabular}{|c|c|c|c|c|}
\hline Conductors & 1 & & & \\
\hline Conductortype & $\begin{array}{l}\text { Average } \\
\text { temperature }\end{array}$ & ng & $\begin{array}{l}\text { Average } \\
\text { temperature }\end{array}$ & ng \\
\hline Traditional steel-cored aluminum strand & 48.94 & .91 & 48.94 & 918. \\
\hline $\begin{array}{l}\text { New steel-cored aluminum strand of high } \\
\text { conductivity }\end{array}$ & 48.57 & .51 & 48.57 & 51 \\
\hline New total aluminum alloy aluminum strand & 43.97 & .96 & 43.97 & 96. \\
\hline $\begin{array}{l}\text { New total aluminum alloy aluminum conductor } \\
\text { of medium tenacity }\end{array}$ & 48.33 & $.87^{73}$ & 48.33 & 87. \\
\hline
\end{tabular}

$$
P=g s l_{h} \sin ^{2} \frac{\theta}{2}+P_{i}
$$

TABLE 4 shows that the vertical loads of the new aluminum alloy cored aluminum strand and new total aluminum alloy conductor of medium tenacity are highly similar and are approximately 10\% lower than that of the traditional steel-cored aluminum strand, whereas the vertical load of the new steel-cored aluminum strand of high conductivity is slightly smaller than that of the traditional steel-cored aluminum strand.

\section{B. Conductor's horizontal load capacity}

The conductor's wind pressure load can be calculated as where $P$ is the conductor's wind pressure load, $N ; \theta$ is the included angle between the conductor and line direction, (.); $g$ is the wind pressure specific load of the conductor, $\mathrm{N} / \mathrm{m} \cdot \mathrm{mm}^{2} ; l_{h}$ is the horizontal span, $m$; and $P_{i}$ is the wind pressure of the insulator string, $N$.

The load of the conductor under gale and icing is obtained according to Formula (8), and the results are shown in TABLE 5 .

TABLE V. CONDUCTOR'S HORIZONTAL WIND LOAD CAPACITY

\begin{tabular}{|c|c|c|c|c|}
\hline Conductor's & & & & \\
\hline$\frac{\text { load capacity }}{\text { Conductor type }}$ & Gale & Icing & Gale & Icing \\
\hline Traditional steel-cored aluminum strand & 36.92 & 8.55 & 36.92 & 8.55 \\
\hline $\begin{array}{l}\text { New steel-cored aluminum strand of high } \\
\text { conductivity }\end{array}$ & 36.86 & 8.54 & 36.86 & 8.54 \\
\hline New total aluminum alloy aluminum strand & 36.86 & 8.54 & 36.86 & 8.54 \\
\hline $\begin{array}{c}\text { New total aluminum alloy aluminum } \\
\text { conductor of medium tenacity }\end{array}$ & 36.86 & 8.54 & 36.86 & 8.54 \\
\hline
\end{tabular}

TABLE 5 shows that the four conductors have highly similar horizontal loads under the same icing thickness.

\section{CONCLUSION}

This paper calculated and compared the mechanical characteristics of three new capacity-expanding and energy-saving conductors and the traditional steel-cored aluminum strand and found that the new steel-cored aluminum strand of high conductivity has superior sag characteristics and icing overload capacity for a typical $500 \mathrm{kV}$ transmission line compared with those of the traditional steel-cored aluminum strands and other new capacity-expanding and energy-saving conductors. The combined load capacity of the new steel-cored aluminum strand of high conductivity is nearly equal to that of the traditional steel-cored aluminum strand and is higher than those of the other two new capacity-increasing and energy-saving conductors. In summary, the new steel-cored aluminum strand of high conductivity has the best sag characteristics, icing overload capacity and combined load capacity.

\section{REFERENCES}

[1]Wan Jiancheng, Dong Yuming, Liu Long, Liu Zhen, Huang Peng, "Performance Comparison and Application Scope of Three Kinds of Energy-Saving Conductors, " Electrical Power,vol.49,no.1,2016, pp.102-108

[2]Sheng Liyuan, “Microstructure Evolution and Mechanical Properties of a Directionally Solidified Nb-Ti-Si-Cr-Al-Hf-Dy Alloy, ” 2016 International Symposium on Materials Application and Engineering (SMAE 2016) Chiang Mai, Thailand.

[3]J.Y.Liu,D.L.Sun.,R.Y.Hong, “ Effect of Organo-Functionalized Silica Particles on the Mechanical Properties of PU, " 2016 5th 
International Conference on Environment, Materials, Chemistry and Power Electronics(EMCPE 2016),Zhen zhou,China.

[4]Huang Peng, Mo Juan, Wan Jiancheng, Zhao Xinyu, “Technical-Economic Analysis on Application of Energy -Saving Conductors in Transmission Lines,'Electric Power,vol.46,no.7,2013, pp.153-157.

[5]Wu Ximao, Dang Peng, Li Chunhe, Wang Jiandong, Wang Fei, "research on newly style conductor," China Electric Power(Technology Edition),Vol.45,No.9,2014,pp.26-28.

[6] Ye Hongsheng. "Application of Moderate-strength All Aluminum Alloy Conductor in Transmission Lines," Electric Power Construction, vol.31,no.12,2010,pp.14-19.

[7] Ding Guangxin etc. "Analysis on Application of Energy- Saving Conductors in Transmission Lines,"Power System Technology,vol.36,no.8,2012,pp.24-30.

[8]Wan Jiancheng, Li Jian, Chen Yuan, Zhu Kuanjun, Liu Zhen, Jiang Ming. "Application of Aluminum Alloy Cored Aluminum Stranded Wire for UHVDC Transmission Line with Large Capacity," Electric Power Construction,vol.34,no.8,pp.2013,105-111.

[9]Chen Yang, “Theory Study On Dynamic Capacity-Increase System Of Transmission Lines Based On Sag," The 2nd National Conference on Information Technology and Computer Science,Shang Hai,China.

[10]Li Suiping, “Economic Analysis of Newly Style Conductor Applied in Technological Updating in Chongqing Power Grid,"Chongqing University,2007.

[11]Ba Hongwu, "the method of calculating the icing overload capacity," Electric Power Construction. vol. 10. no. 5,pp.30-33.

[12]Zhen Jiang. “Design Method of Synthetic Load of Ice Conductors in Transmisson Line,"High Voltage Engineering,vol.20,no.2,pp.94-95.

[13] Yang Fengli, Yang Jingbo, Fu Dongjie, Li Qinghua. “Analysis on the Loads From Galloping Conductors of Transmission Lines,” Proceedings of the CSEE, vol. 31, no.16,2011,pp.102-107. 